\title{
Mesopotamian cylinder seal from Lori Berd (Armenia): An object in an unusual location?
}

The objective of the article is the study on an unpublished chalcedony cylinder seal found in 2008 in the Achaemenid era burial No. 106 of Lori Berd ${ }^{1}$, Armenia.

The seal from Achaemenid tomb No 106 of Lori Berd has the form of a cylinder made of pinkish chalcedony with gold caps on gold pin (Fig. 1). The cylinder seal by itself has $2.8 \mathrm{~cm}$ height and $1.1 \mathrm{~cm}$ in diameter. With the mountings the height of the seal is $4.1 \mathrm{~cm}$.

The main scene makes a standing figure, a so called hero, which seizes two upstanding goats from right and left sides (Fig. 2, 3).

The rest of the surface is almost equally covered by filling motifs: pleiades ( $A k k$ "sibittu"), star of Ishtar, stylus of Nabu, lozenge, so called "ball-and-staff, fish and crouching monkey.

The similarities of the cylinder seal from Armenia with the seal of Urzana (Fig. 4) and other related seals (E.g. combat scenes from British Museum ${ }^{2}$ ) suggest that the examined cylinder seal should be dated from late $8^{\text {th }}$ century to $7^{\text {th }}$ century BCE.

The observation of the cylinder seal from Lori Berd shows Neo-Assyrian and NeoBabylonian influences. Some features such as goates, symbol of god Nabu, the short skirt of the hero, top knot haircut and the relative hard material for the seal suggest that here we deal with Babylonian rather than Assyrian influence ${ }^{3}$.

The practice of using a Neo-Babylonian cylinder seal in Achaemenid period can be observed in the palace of Persepolis, where the wife of Darius I (522-486 BCE) Irtašduna (Greek "Aristone") was using a Neo-Assyrian or Neo-Babylonian cylinder seal to seal official documents ${ }^{4}$ (Fig. 5).

The use of Neo-Assyrian seal by the wife of Darius and other archaeological materials of the tombs (glass vessel, silver bowl etc) give ground to suppose that the owner of the seal was aware of the customs of Achaemenid elite or even had some contacts to the king's court. Such a person could be a local chief or administrative officer.

\footnotetext{
1 Lori Berd is an archeological site in Armenia which covers Bronze and Iron Ages. See Devejyan 1981 for the tombs of Late Bronze and Iron Age; See Devejyan 2006 for the settlement and tombs of Middle Bronze Age.

2 Collon 2001, PI. 29.

3 Porada 1947, 162; 1948, 98-99; Wittmann 1992, 192-193, 209-212; Herbordt 1992, 92; Collon 2001, 167; Fügert 2013, 61-69.

${ }^{4}$ Garrison - Root 2001, 83-85, PI. 10, 11, see Seidel 2005, 157 for the identification as a Neo-Assyrian seal.
} 
Figures: 1. Photo of the cylinder seal of Lori Berd (S. Devejyan private archive)

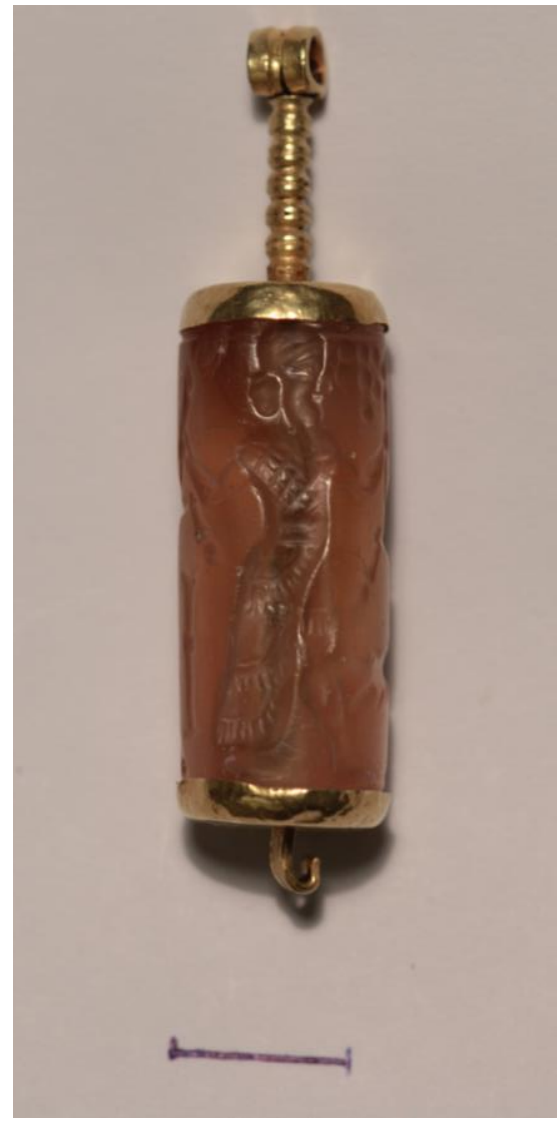

2. Seal impression (S. Devejyan private photoarchive)

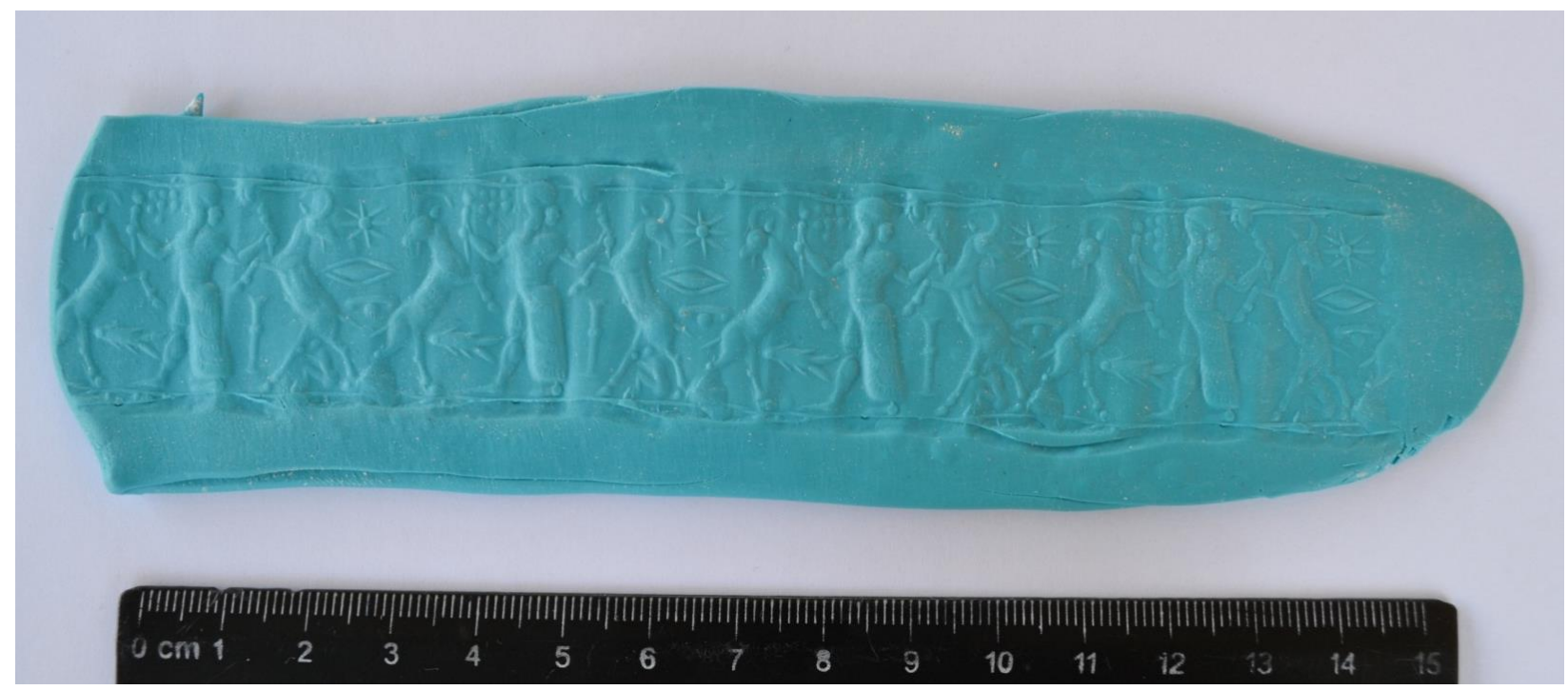




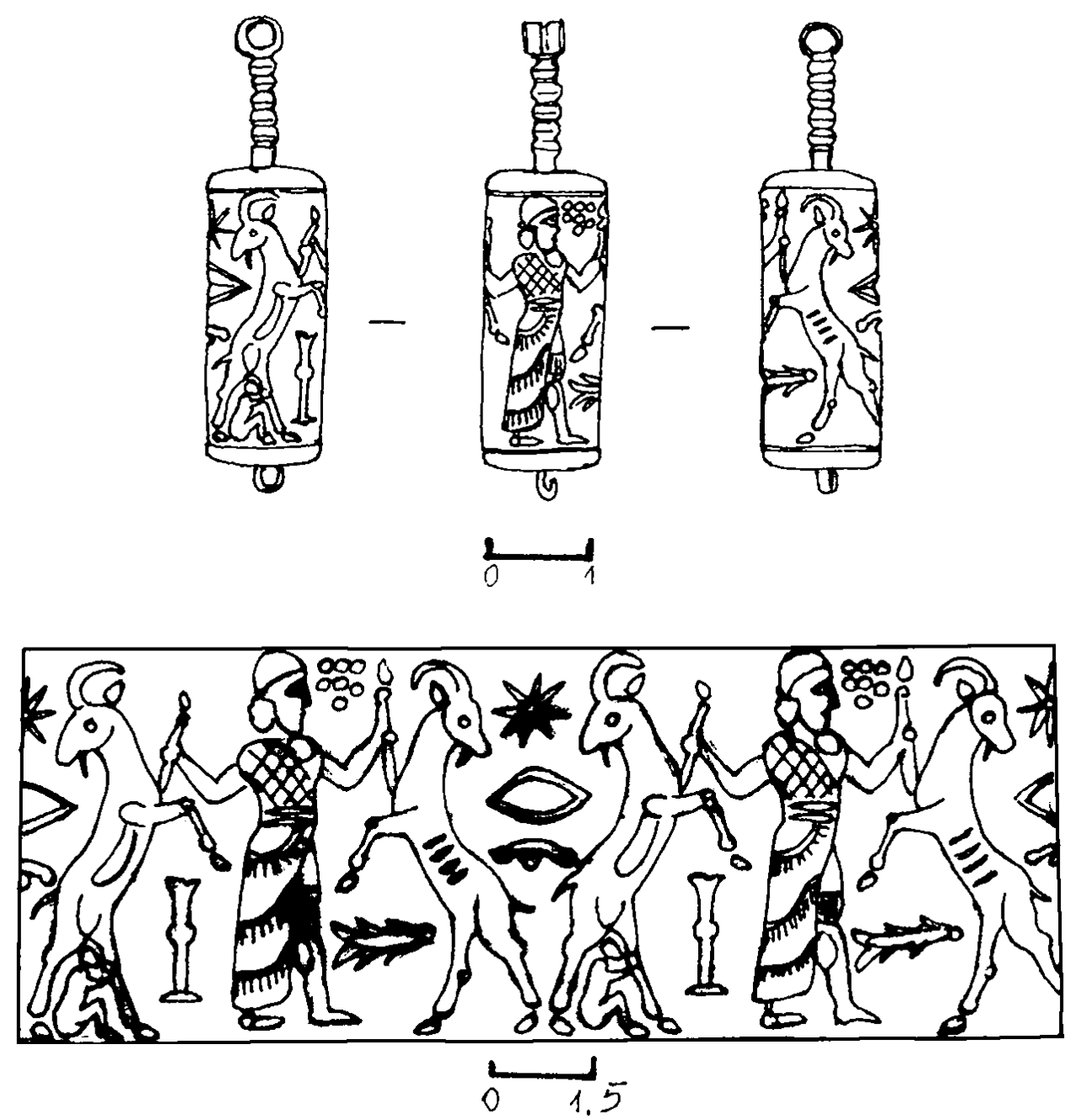
3. Drawing of the seal and the picture of the seal

4. Seal impression of seal of Urzana (Radner 2007, Fig. 17.02)

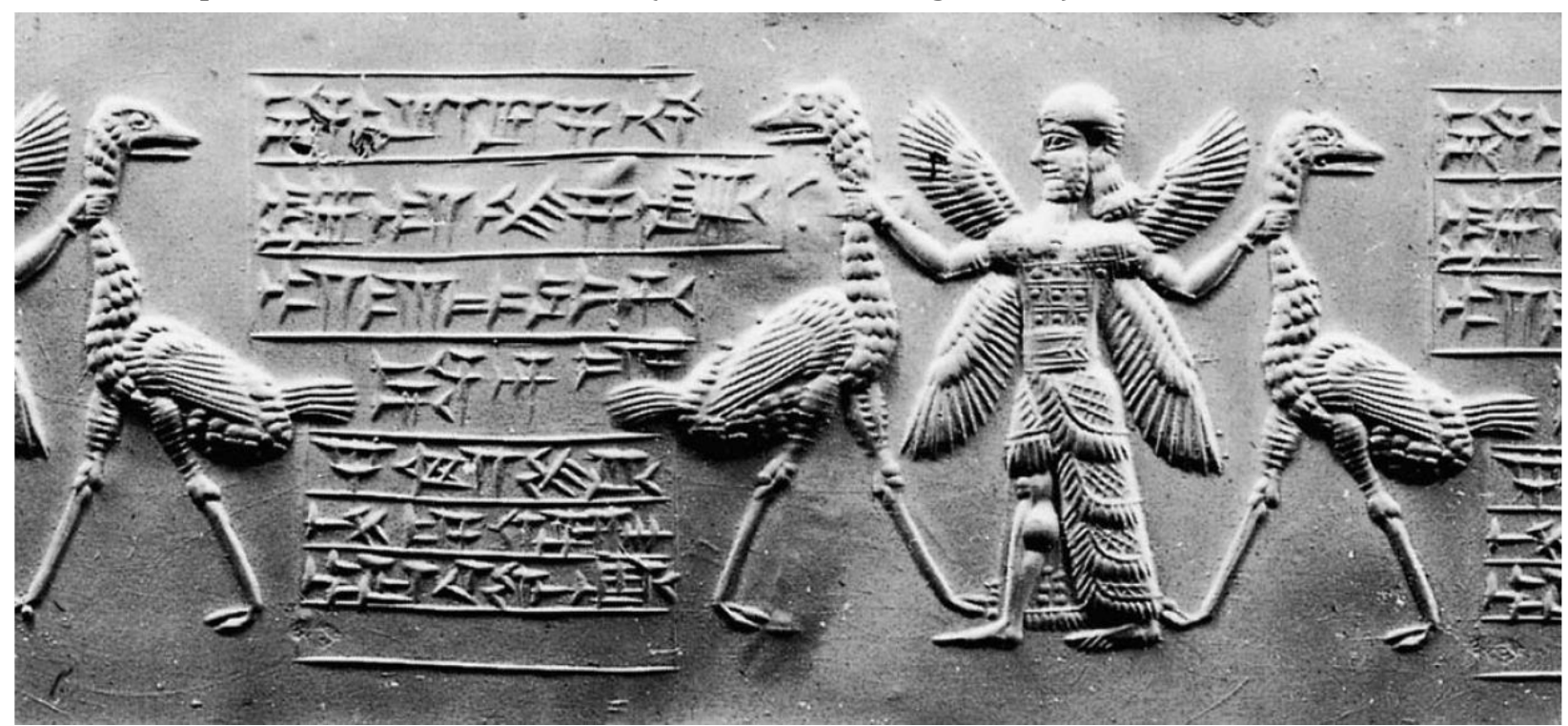

